\title{
Las acciones del gobernador José de Barrasa en los litigios territoriales con Francia en Río Muni
}

\section{Miquel Vilaró i Güell}

Universitat Autònoma de Barcelona. Departament de Geografia miquel.vilaro@uab.cat

Recepción: marzo de 2010 Aceptación: septiembre de 2011

\section{Resumen}

En el contexto inmediato a la Conferencia de Berlín de 1885, el acuerdo tácito al que finalmente llegaron Alemania y Francia de situar en el río Campo el límite de sus respectivas colonias en la región del Muni, ignorando la frágil soberanía espańola allí ejercida, ocasionó numerosos incidentes entre España y Francia, incluso después de que ambas «naciones amigas» pactasen un statu quo permanente en tanto no se resolviese por la vía diplomática el deslinde definitivo de sus fronteras. Sólo la actuación firme de algunos gobernadores atentos a las instrucciones del Comité Ejecutivo de la Sociedad Española de Africanistas y Colonistas ${ }^{1}$ logró frenar el ímpetu francés de expulsar a España de la región continental. El propósito de este artículo es poner de relieve las decisivas actuaciones del gobernador José de Barrasa y Fernández de Castro en tan enmarañado asunto.

Palabras clave: Guinea Española; Guinea Ecuatorial; colonización; historia de África; geografía histórica.

Resum. Les accions del governador José de Barrasa en els litigis territorials amb França a Rio Muni

En el context immediat a la Conferència de Berlin de 1885, l'acord tàcit al qual finalment van arribar França i Alemanya de situar en el riu Campo el llindar de les fronteres mútues a la regió del Muni, fent cas omís de la feble sobirania que Espanya hi exercia, va donar lloc a nombrosos incidents entre Espanya i França, àdhuc després que totes dues «nacions amigues» pactessin un statu quo permanent, mentre no es resolgués per via diplomàtica el traçat definitiu de les seves fronteres. Tan sols l'actuació ferma d'alguns governadors atents a les instruccions del Comité Ejecutivo de la Sociedad Española de Africanistas y Colonistas va aconseguir posar fre a l'abrivament francès d'expulsar Espanya de la regió continental. El propòsit d'aquest article és destacar les actuacions decisives en un assumpte tan embolicat dutes a terme pel governador José de Barrasa y Fernández de Castro.

Paraules clau: Guinea Espanyola; Guinea Equatorial; colonització; història d’Àfrica; geografia històrica.

1. Transformada en 1885 en la Sociedad Española de Geografía Comercial. 
Résumé. Les interventions du gouverneur José de Barrasa dans les litiges territoriales avec la France au Río Muni

Dans le contexte immédiat de la Conférence de Berlin de 1885, l'accord tacite atteint finalement pour l'Allemagne et la France de situer au río Campo les limites de leurs colonies respectives à la région du Muni, en ignorant la fragile souveraineté espagnole là exercée, a provoqué de nombreux incidents entre l'Espagne et la France, même après que les deux "pays amis» se sont mis d'accord sur un statu quo, en attendant une solution diplomatique à la délimitation définitive de leurs frontières. Seule la bonne performance de certains gouverneurs attentifs aux instructions du Comité Ejecutivo de la Sociedad Española de Africanistas y Colonistas a arrêté l'élan français d'expulser l'Espagne de la région continentale. Le but de cet article est de mettre en évidence les actions décisives du gouverneur José de Barrasa y Fernández de Castro dans une question si embrouillée.

Mots clé: Guinée Espagnole; Guinée Équatoriale; colonisation; histoire de l'Afrique; géographie historique.

\section{Abstract. The interventions of Governor José de Barrasa in the territorial disputes with France in Rio Muni}

In the context of the Berlin Conference of 1885, the agreement finally reached by Germany and France to establish the boundaries of the countries' respective colonies at the River Campo of the Muni region ignored Spanish sovereignty over the region. This led to numerous incidents between France and Spain, even after both "friendly nations» signed a permanent status quo to establish their frontiers. The intervention of certain governors under the instructions of the executive committee of the Sociedad Española de Africanistas y Colonistas managed to prevent the French from expelling the Spanish from the continent. The purpose of this article is to draw attention to the decisive roles played by governors Jose de Barrasa and Fernandez de Castro in this embroiled chapter of history.

Keywords: Spanish Guinea; Equatorial Guinea; colonisation; African history; historical geography.

\section{Sumario}

Introducción Las presiones francesas sobre Bata

Los antecedentes en el propósito franco-alemán de expulsar a España de la región del Muni

El criterio del gobernador José de Barrasa en los pleitos territoriales por la indefinición de límites

La impugnación de las pretensiones y río Benito

La instrumentalización de las misiones religiosas en el despliegue francés

La voluntad francesa de arrinconar a España

Referencias bibliográficas 


\section{Introducción}

Previo a analizar el objeto de este artículo, debe señalarse que la evaluación del pasado colonial de España en el golfo de Guinea aún no se ha llevado a cabo como es debido, y mucho menos desde la perspectiva que puede ofrecer la geografía histórica. Los trabajos de investigación, realizados hasta la fecha de manera casi exclusiva por historiadores y antropólogos, son relativamente escasos y centrados en visiones de conjunto (Castro y Calle, 1992; Nerín, 1997; García Cantús, 2006) o en análisis amplios de aspectos concretos como la política colonial y el mercado de trabajo (Sanz, 1983), la colonización religiosa (Creus, 1998), el tráfico de esclavos y la expansión económica (Díaz Matarranz, 2005) o el derecho colonial (Carrasco, 2007); por citar algunos ejemplos, siendo más bien pocos los estudios sobre aspectos puntuales pero significativos en este proceso.

El parvo interés que despierta en la actualidad entre los geógrafos españoles el colonialismo español en África negra es una incógnita, y más si tenemos en cuenta las muchas pesquisas que podrían llevarse a cabo sobre cuestiones claramente geográficas, como las estrategias territoriales que se siguieron, las vicisitudes económicas y sociales que se dieron, el papel desempeñado por las sociedades geográficas o los avatares geopolíticos que afectaron a los casi dos siglos de permanencia de España en el golfo de Guinea. Quizás la respuesta se encuentre en la mayor visibilidad que los departamentos universitarios logran con estudios de geografía aplicada, lo que va en detrimento de la menos rentable reflexión teórica, víctima de un cierto demodé que esperamos que sea solo transitorio.

En todo caso, en las reflexiones sobre el colonialismo de los siglos XIX y $\mathrm{xx}$, existe una clara asimetría entre la mayor atención que desde nuestra disciplina se ha prestado a la presencia española en Marruecos durante los tiempos del Protectorado - en aspectos tan diversos como la valoración de la influencia ejercida por las sociedades geográficas (Rodríguez Esteban, 1996; Pedraz, 2000), la organización del territorio (Villanova, 2004), la catalogación de las aportaciones de los naturalistas (González y Gomis, 2007) o el análisis de las percepciones de los viajeros y las viajeras españoles que allí se desplazaron (Garcia Ramon et al., 2008; Cerarols, 2008) - y los pocos trabajos sobre temas guineanos realizados en estos últimos años desde una perspectiva geográfica (Vilaró, 2011).

Una lectura actual que explote desde la geografía todo lo que significó la antigua Guinea española es sin duda una asignatura pendiente. En este sentido, este artículo pretende cubrir uno de sus muchos flecos al valorar, en un contexto determinante, un aspecto puntual y significativo: el papel desempeñado por la Sociedad Española de Colonistas y Africanistas en la defensa de los derechos de España en la región del Muni y el protagonismo ejercido sobre el terreno por el gobernador José de Barrasa y Fernández de Castro. 


\section{Los antecedentes en el propósito franco-alemán de expulsar a España de la región del Muni}

La primera voz de alarma sobre las intenciones franco-alemanas de expulsar a España de la región continental la dio el gobernador de Fernando Poo Antonio Cano en mayo de 1884, después de haber realizado una gira con la goleta Ligera por la bahía de Corisco. En aquella ocasión, el gobernador dio detallada cuenta de que las autoridades gabonesas habían establecido, desde agosto de 1883 en Punta Elobey, a solo cuatro millas al sur de la desembocadura del río Muni, "un delegado del gobierno francés en una casa construida al efecto", advirtiendo que era público y notorio el rumor de que Francia tenía «verdadero interés en posesionarse del trozo de costa que pertenece a España», aprovechando la circunstancia de no estar debidamente deslindados los territorios y el hecho lamentable de la nula presencia española en aquellos parajes por falta de un buque de guerra ${ }^{2}$.

Para evitar conflictos con una "nación amiga», Cano recomendó al Gobierno la adopción de dos medidas urgentes e imprescindibles: la formación de una comisión franco-española para que se marcasen definitivamente los límites territoriales en la bahía de Corisco y la creación de un subgobierno en la isleta de Elobey Chico en manos de un alférez de navío, "quien podría tener a sus órdenes la lancha de vapor Trinidad, embarcación muy a propósito para recorrer con ella nuestras distintas posesiones de la bahía de Corisco y remontar gran número de leguas el río Mooney, principal venero de riqueza de aquella localidad».

Como resultado de las advertencias del gobernador, el Comité Ejecutivo de la Sociedad Española de Africanistas y Colonistas, emanada del Primer Congreso de Geografía Colonial y Mercantil celebrado en Madrid en noviembre de 1883, decidió organizar, de inmediato y en nombre propio, una expedición de toma de posesión de toda la costa comprendida entre Calabar y Cabo Santa Clara, tenida por española en virtud de los tratados de San Ildefonso y el Pardo firmados con Portugal a finales del siglo $\mathrm{XVIII}^{3}$, para la que designó dos delegados: el explorador Manuel Iradier, protagonista de una primera y peculiar experiencia exploratoria en el Muni entre los años 1874-1876, y el médico asturiano Amado Ossorio, destacado miembro de la Sociedad Geográfica de Madrid.

Conforme a la crónica que Iradier escribió sobre esta segunda expedición, cuando la comitiva llegó a Fernando Poo el 24 de agosto, después de un mes

2. Archivo General de la Administración (AGA). África-Guinea (A-G). Caja (C) 81/7056. Dando cuenta de la salida de la goleta "Ligera", conduciendo al Gobernador en su visita a las Posesiones Españolas de la Bahía de Corisco. Santa Isabel de Fernando Poo, 31 de mayo de 1884.

3. Los pormenores de los derechos de España en el Muni y de los territorios aun sin ocupar fueron expuestos por Joaquín Costa y Francisco Coello a Antonio Cánovas del Castillo (presidente del Consejo de Ministros) en una extensa carta fechada el 17 de octubre de 1884 (AGA. A-G. C 81/7056). 
de azaroso viaje, era ya demasiado tarde: los territorios al norte del río Campo acababan de ser incorporados a Alemania e Inglaterra. Los situados al sur, hasta el cabo Santa Clara, adquiridos por España en 1843 y 1858, acababan también de ser invadidos y ocupados por alemanes y franceses, por lo cual no quedaba en toda la costa más punto libre que la boca del Muni, en la que Francia estaba ya realizando movimientos de ocupación. De haber llegado la expedición pocas semanas antes, España quizás hubiese podido hacerse con todo este gigantesco territorio. En aquellos momentos, la única empresa posible era asegurar la soberanía sobre el estuario del Muni y sus ríos tributarios (Iradier, 1885: 163-189).

Según Iradier, el resultado de la misión fue «haber obtenido para la Sociedad de Africanistas y Colonistas de Madrid la soberanía de ciento un jefes indígenas de las tribus pamues, vicos, bijas, itemus, bundemus, velengues, dibues, bujebas, etc.», lo que comprendía una extensión de $14.000 \mathrm{~km}^{2}$, con cartas de cesión autentificadas por el notario de Fernando Poo, Bernabé Jiménez Blázquez, integrante de la expedición ${ }^{4}$. Sin embargo, la facilidad con que los jefes indígenas otorgaban este tipo de documentos a los «diplomáticos» que más obsequiosos se mostraban, cuantas veces les parecía y sin reparar a qué país pertenecían, rebajaba sustancialmente su valor legal. Unas fiebres inoportunas contraídas de regreso de la expedición obligaron a Iradier a retornar a la Península, de modo que Amado Ossorio se quedó refugiado en Elobey a la espera de nuevas instrucciones.

Por su lado, igualmente a finales de año, el gobernador Cano advirtió de la presencia de una escuadra alemana en el río Camarones formada por la corveta Bismarck y otros tres buques de guerra, cuya tropa había emprendido una contundente acción de represión contra los negros que habían secuestrado a un factor alemán de la casa Woermann. Asimismo, dio cuenta de que, durante su estancia en Elobey, se le habían presentado jefes indígenas con contratos firmados con la Sociedad de Africanistas y al mismo tiempo con las autoridades civiles y eclesiásticas del Gabón. De tres de ellos, se remitió copia al ministro de Marina 5 .

Para mayor desconcierto del Gobierno y revuelo en los plenipotenciarios españoles que participaban en la Conferencia de Berlín ${ }^{6}$, el nuevo goberna-

4. Conforme a la documentación entregada por Manuel Iradier al gobernador de Fernando Poo el 13 de diciembre de 1884, y remitida de inmediato al ministro de Ultramar, los contratos firmados con los jefes fueron $80 \mathrm{y}$ alcanzaron un área de $10.000 \mathrm{~km}^{2}$, con una población de unos 50.000 habitantes. La relación nominal de los 80 jefes firmantes puede consultarse en AGA. A-G. C 81/7123 E 15. Sociedad Española de Africanistas y Colonistas.

5. Archivo General de la Marina Álvaro de Bazán (AGMAB). Legajo 1176/431. Corveta Ligera. Oficio del gobernador Antonio Cano al Ministro de Marina, 26 de diciembre de 1884.

6. El ministro plenipotenciario era el conde de Benomar (Francisco de Paula Merry y Colom) y el «delegado técnico», Francisco Coello y Quesada, presidente de la Sociedad Geográfica de Madrid. En agosto de 1884, el conde confirmó que Alemania había tomado posesión de "Camarones y bahía de Bimbia en la Costa norte del golfo de Guinea», 
dor de Fernando Poo, José Montes de Oca, al regresar de una gira por Corisco y la región continental en marzo de 1885, también con la Ligera ${ }^{7}$, añadió la noticia de que los franceses, "por engaño o a la fuerza», habían establecido un pequeño puesto militar y una misión religiosa en la desembocadura del río Benito, razón por la que el territorio comprendido desde la margen izquierda de este río hasta Italomanga, muy cerca del cabo San Juan, estaba sembrado a intervalos de banderas francesas y alemanas, «pues entre las dos naciones parece se han propuesto despojarnos de todo el territorio que de derecho nos pertenece» ${ }^{8}$.

Las informaciones poco favorables facilitadas por Iradier a la Sociedad de Africanistas en febrero de 1885, junto con las advertencias de Montes de Oca, movieron a Joaquín Costa, en nombre del Comité Ejecutivo de la Sociedad y en calidad de "Director de expediciones», a tomar cartas en el asunto, proponiendo al Gobierno la adopción de medidas inmediatas y definitivas para consolidar la frágil soberanía española en el Muni.

Así, el día 27 de abril de 1885, Costa dirigió una carta a Antonio Cánovas del Castillo, presidente del Consejo de Ministros, en la cual le recordaba — de forma premonitoria sobre lo que realmente sucedería quince años más tarde- que el explorador francés Mr. Brazza trabajaba para enlazar la colonia del Gabón con las nuevas posesiones francesas del Congo, por lo que en breve se proponía remontar el río Benito «a fin de explorarlo e ir incorporando a su nación las tribus de ambas riberas, hasta unir políticamente aquella cuenca con las de los ríos franceses Gabón y Ogüé, y recluir a España en su pequeño territorio del Muni, cerrándole el paso hacia el interior y haciendo imposible el desarrollo a esa posesión española del continente»" ${ }^{9}$, motivo más que suficiente para que, en su opinión, resultara perentorio organizar con toda reserva "dos o tres expediciones» hacia el interior con el fin de anexionar las partes alta y media de aquellos ríos que se hallaban todavía sin ocupar.

Siguiendo las recomendaciones de Costa, el Gobierno emitió acto seguido una Real Orden reservada (29 de abril) para que el miembro de la Sociedad Española de Africanistas y Colonistas que se hallaba en Elobey (Amado Ossorio), obrando simultáneamente con las autoridades de la colonia, emprendiese una expedición, dividida en dos o tres secciones, para remontar

circunstancia que, a su juicio, recomendaba tomar posesión efectiva del territorio de Cabo San Juan, procurando proceder amistosamente con Alemania en todo lo relativo a los límites de las posesiones respectivas o a los intereses de ambas potencias en el golfo de Guinea (AGA. A-G. C 81/7056. Despacho no 265. Berlín, 22 de agosto de 1884).

7. AGMAB. Legajo 620/775. Hoja de servicios del capitán de fragata José Montes de Oca y Aceñero.

8. AGA. A-G. C 81/7060. Oficio del gobernador José Montes de Oca al ministro de Ultramar. Santa Isabel de Fernando Poo, 21 de abril de 1885.

9. AGA. A-G. C 81/7060. Carta dirigida al presidente del Consejo de Ministros por Joaquín Costa, en nombre del Comité ejecutivo de la Sociedad Española de Africanistas. Madrid, 27 de abril de 1885 . 
«sin pérdida de tiempo y con toda reserva los ríos Benito y Campo», distribuyendo documentos de anexión "a las tribus ribereñas de ellos y sus afluentes, a partir del punto extremo a donde hayan llegado las anexiones francesas y alemanas» ${ }^{10}$.

El principal obstáculo para llevar a cabo las tres ambiciosas expediciones que de inmediato propuso desde Santa Isabel el gobernador Montes de Oca - la primera por los ríos Noya y Utamboni, afluentes del Muni; la segunda por los ríos Dote y Benito, hasta llegar al extremo norte de la cordillera del Cristal, y la tercera por el río Campo, hasta sesenta millas hacia oriente, donde se le unirían las otras dos para dirigirse juntas al monte Bumby- fue la falta de recursos. Lamentándose de que para gastos solo disponía de tres mil pesos de su bolsillo procedentes de su hacienda particular de Basilé, más dos mil que le había prestado la misión de los Hijos del Inmaculado Corazón de María, por no haber fondos disponibles en la Caja de la Colonia, pidió que desde Madrid se le mandasen cincuenta mil pesos con toda urgencia. Montes de Oca no consideraba exagerada esta cantidad, pues el explorador Pierre Savorgnan de Brazza llevaba para su expedición seis millones de francos ${ }^{11}$.

En las prisas, Francisco Coello, Joaquín Costa y Rafael Torres Campos, sintiendo que la Sociedad de Africanistas no dispusiera de tiempo para organizar por sí misma las proyectadas expediciones, intentaron sin resultado que Cánovas del Castillo mediara en el envío de por lo menos los fondos más imprescindibles, amparándose en que las Cortes Generales habían aprobado recientemente una partida de 100.000 pesetas para exploraciones ${ }^{12}$. No obstante, el primer dictamen emitido por el Ministerio de Estado, aun reconociendo la conveniencia de sostener el derecho que se pudiera tener en el litoral africano, rebelaba ya la escasa predisposición del Gobierno para secundar los acelerados y dispendiosos planes de la Sociedad: «La creación de ese vasto imperio que la Sociedad de Africanistas ambiciona habría de implicar cuantiosos gastos para los cuales carecemos de recursos, y cuyo pensamiento, por tanto, es sin duda irrealizable» ${ }^{13}$.

Al final, desde Madrid, se remitieron tan solo los cinco mil duros adelantados y se ordenó al perplejo gobernador que «atendida la falta de medios pecuniarios, limitara a 5.000 pesos el gasto de las operaciones» ${ }^{14}$, por lo que

10. AGA. A-G. C 81/7060. Real Orden reservada al Gobernador Gral., a fin de que remonte los ríos Benito y Campo, y distribuya documentos de anexión a las tribus ribereñas de ellos y sus afluentes. Madrid, 29 de abril de 1885.

11. AGA. A-G. C 81/7060. Oficio reservado del gobernador Montes de Oca al ministro de Ultramar. Santa Isabel, 5 de julio de 1885.

12. AGA. A-G. C 81/7060. Carta dirigida por Coello, Costa y Torres Campos a Cánovas del Castillo. Madrid, 19 de agosto de 1885.

13. AGA. A-G. C 81/7123. Dictamen del Ministerio de Estado en respuesta a la petición dirigida por Francisco Coello el 31 de julio de 1885.

14. AGA. A-G. C 81/7060. Sobre recursos pedidos por el Gobernador para el cumplimiento de la R. O. reservada de 29 de abril. Madrid, 16 de octubre de 1885. 
el plan inicial se contrajo sustancialmente y quedó reducido a una única expedición dividida en varias etapas.

La comitiva, formada por Montes de Oca, Ossorio, cinco voluntarios cubanos y un centenar de bagajeros, salió de Santa Isabel el 16 de julio de 1885 en dirección al río Noya en el estuario del Muni, con la intención de alcanzar las montañas de la Sierra de Cristal y desde allí acceder al río Benito desde el interior. Sobre la marcha, Montes de Oca y Ossorio pronto pudieron comprobar que ni su primer objetivo se cumpliría, al no encontrar guías dispuestos a conducirles por unos territorios habitados por tribus enemistadas. Ello les obligó a retroceder y salir de nuevo a la costa para dirigirse desde allí al río Benito, con el consiguiente sobrecoste y retraso. Además, las dificultades de financiación enseguida se hicieron acuciantes, porque los porteadores contratados para transportar la carga no aceptaban créditos contra el Gobierno ${ }^{15}$.

Como no podía ser de otra manera, los resultados de la expedición — que finalmente pudo llevarse a cabo más por empeño de sus protagonistas que por impulso del Gobierno- fueron mucho más modestos que los proyectados en un principio por Montes de Oca, aunque no desdeñables si tenemos en cuenta los escasísimos recursos económicos y humanos con que contaron. A pesar de los contratiempos, se pudo verificar que tanto el río Campo al norte como el río Noya al sur alcanzaban unas coordenadas geográficas mayores a las conocidas, con lo que los límites de los territorios que podían ser reivindicados por España se ensanchaban notablemente. A la vez, se comprobó que los pamues no eran tan temibles como se creía, lo que convertía la ocupación de las regiones interiores en un objetivo perfectamente asumible ${ }^{16}$. Sin embargo, no haber conseguido penetrar más de dos grados de longitud por el interior del continente, en el espacio comprendido entre los ríos Campo y Noya, constituía un acervo demasiado frágil para poner en jaque el bien nutrido ímpetu francés.

El desacuerdo de las autoridades francesas frente a estas modestas iniciativas exploratorias españolas propició la creación en París, en mayo de 1886, de la comisión francoespańola sugerida dos años antes por Antonio Cano, la cual entró rápidamente en un callejón sin salida por tratarse de dos criterios diametralmente opuestos. Ello propició el establecimiento de un statu quo en la región, en septiembre de aquel mismo año, sujeto a tres ambiguas bases:

1. La completa libertad de comercio para los súbditos españoles y franceses, tanto en tierra como en las embarcaciones.

2. La abstención de todo acto que implicase la pretensión o expresión de soberanía sobre los territorios en litigio.

15. AGA. A-G. C 81/7073. Oficio del gobernador Montes de Oca al ministro de Ultramar. Kororo, en el río Utamboni, 26 de agosto de 1885.

16. AGA. A-G. C 81/7056. Memoria de Francisco Coello dirigida al ministro de Estado sobre las exploraciones y anexiones de 1885-85. Madrid, 14 de agosto de 1884. 
3. La no consideración de las banderas usadas por las casas comerciales como pabellones nacionales ${ }^{17}$.

Tan enquistado affaire no se resolvería hasta junio de 1900 en el Tratado de París, pero, desde su mismo inicio, los criterios adoptados sufrieron continuas rupturas por parte francesa. Solo la actuación firme de los gobernadores españoles de turno logró contenerlos en parte y evitar que sentaran precedente. El primero de estos gobernadores fue José de Barrasa y Fernández de Castro, cuyo firme proceder sirvió de pauta a sus sucesores en el cargo.

\section{El criterio del gobernador José de Barrasa en los pleitos territoriales por la indefinición de límites}

El inicio de las negociaciones que se seguían en París coincidió con el nombramiento de José de Barrasa como comandante de la goleta mixta Ligera, con destino en el golfo de Guinea, y, a la vez, como gobernador interino de Fernando Poo por ausencia de su titular, José Montes de Oca, y en sustitución del también interino José de Ibarra, quien había ejercido como tal durante los cinco días anteriores a su llegada.

Sin duda alguna, los siete meses escasos de esta primera permanencia de José de Barrasa al frente de la colonia africana (del 3 de mayo de 1886 al 2 de enero de 1887) fueron decisivos, tanto para la contención inicial del expansionismo franco-alemán en el Muni, como para la delimitación de un territorio que Espańa iba a reivindicar con ahínco durante los largos ańos en que estaría vigente el statu quo.

Así, a mediados de agosto, poco antes de que las negociaciones se estancaran y se adoptase el mencionado statu quo, el nuevo gobernador interino, como resultado de un encontronazo en el río Muni con el comandante del aviso francés Laprade — que más adelante comentaremos-, dirigió un oficio al ministro de Ultramar en el que, por primera vez, vemos reflejado sin ambages no solo la opinión de un gobernador sobre la importancia y el alcance territorial de la región del Muni, sino también la estrategia que debía seguirse para acudir a las negociaciones parisinas con un as en la manga.

En relación con el valor del Muni, el criterio de De Barrasa no puede ser más claro: la posesión por España de toda la cuenca es de «interés capital», porque su comercio en productos de gran valor, como la goma, el ébano y el marfil, es "susceptible de mucho desarrollo». Con ella, se tiene "la base de una colonia muy rica»; sin ella, las islitas que España posee en la bahía de Corisco pierden todo su valor «y no nos resarcirían nunca los gastos que hiciéramos para su conservación» ${ }^{18}$.

17. AGA. A-G. C 81/7065. E 5. 1890. Establecimiento del statu quo en Guinea, convenido entre España y Francia. R.O. comunicada por el ministro de Ultramar. Madrid, 31 de diciembre de 1890.

18. AGA. A-G. C 81/7071. Oficio del gobernador De Barrasa al ministro de Ultramar exponiendo los límites de la colonia. Santa Isabel, 16 de agosto de 1886. 
En cuanto al ámbito territorial que se debía reivindicar, el gobernador se muestra por primera vez plenamente consciente de que Alemania se conformará en extender su frontera del Camerún hasta la orilla derecha del río Campo y no crear más problemas si España acepta este límite ${ }^{19}$, por lo que, «no teniendo absolutamente ninguna orden ni indicación del Gobierno de SM» $\mathrm{y}$ «no habiendo Jefes a quienes se les hubiera dado banderas ni saludos más arriba de este río", cree que lo más sensato es dar por buena la propuesta del káiser de retirarse definitivamente al norte del río Campo ${ }^{20}$ y concentrar los esfuerzos en frenar la pretensión francesa de extender sus dominios hasta alcanzar la nueva frontera alemana, con lo cual negaba el buen derecho de España a poseer una colonia en el continente. Con semejante idea, cree necesario actuar con astucia y hacer valer los tratados de cesión de Portugal para pretender algo en posesión de Francia que pueda servir en las negociaciones de París "como materia de transacciones", por lo que sitúa como límite sur de las posesiones españolas el cabo Santa Clara, incluyendo, por tanto, el río Mundah, una cuenca que España reconocía como francesa desde 1860 (mapa 1).

Aun a sabiendas de que el Mundah hacía dos décadas que estaba bajo control francés, motivo por el que no podía ser otra cosa que una dudosa pieza de trueque, los límites señalados por De Barrasa quedaron oficiosamente establecidos y perfilados en el mapa que Francisco Coello publicó en 1890 en el Boletín de la Sociedad Geográfica de Madrid ${ }^{21}$, donde el espacio comprendido entre el río Campo y el cabo Santa Clara queda proyectado, en virtud de una interpretación personal de los acuerdos alcanzados por las potencias coloniales en la Conferencia de Berlín de 1885, hasta 17 grados al este del meridiano de Greenwich, en la frontera con el Estado Libre del Congo ${ }^{22}$, con lo cual se hizo creer a la clase política y a la opinión pública que España tenía derecho, en el interior del continente africano, a una franja rectangular de más de $190.000 \mathrm{~km}^{2}$ de superficie.

\section{La impugnación de las pretensiones territoriales de Francia}

Por parte francesa, los criterios eran muy distintos, especialmente después de que la cancillería alemana renunciara, a finales de 1885 , a los territorios

19. Francisco Coello, durante su participación como delegado técnico en Berlín, propuso al conde de Benomar el río Campo como límite norte máximo de los derechos de España en la costa occidental de África, aunque reconociendo que este derecho se hallaba «dudoso» entre este río y el río Benito, el cual consideraba como límite mínimo. AGA. A-G. C 81/7056. Despacho no 352. Berlín, 14 de noviembre de 1884.

20. El propósito de Alemania de retirarse al norte del río Campo había sido apalabrado entre el Conde de Benomar y el ministro de Negocios Extranjeros alemán (conde de Hatzfeldt), paralelamente a la Conferencia de Berlín, sin que se formalizase ningún tratado.

21. Boletín de la Sociedad Geográfica de Madrid (BSGM). Tomo XXIX. Segundo semestre de 1890.

22. AGA. A-G. C 81/7059. Golfo de Guinea. Boletines de la Sociedad Geográfica remitidos por el Señor Coello y en los cuales se habla de nuestras posesiones en el golfo de Guinea. 
situados al sur del río Campo. Amparándose en unos dudosos acuerdos comerciales alcanzados en 1842 con algunos cabecillas de la zona, y argumentando que el territorio español empezaba en la orilla sur del río Aye y se limitaba a los territorios circunscritos en las cercanías de Cabo San Juan, las autoridades del Gabón empezaron a repartir banderas por toda la región continental, especialmente en los poblados situados en el estuario del río Muni, donde se habían establecido algunas factorías francesas en la isla Gande y en diversos puntos del Utamboni, protegidas por el buque de guerra francés Basilic, que regularmente entraba en el río con la excusa de relevar a las cañoneras y reportarlas de víveres. Con la idea de aprovechar cualquier pretexto para sentar precedentes en su pretensión de adueñarse de la región, los incidentes no tardaron en producirse y subieron de tono cuando las iniciativas francesas de ocupación se trasladaron también al río Benito.

Así, el primer episodio se dio cuando el comisario superior de Libreville dirigió dos comunicaciones de protesta a De Barrasa. La primera contra el

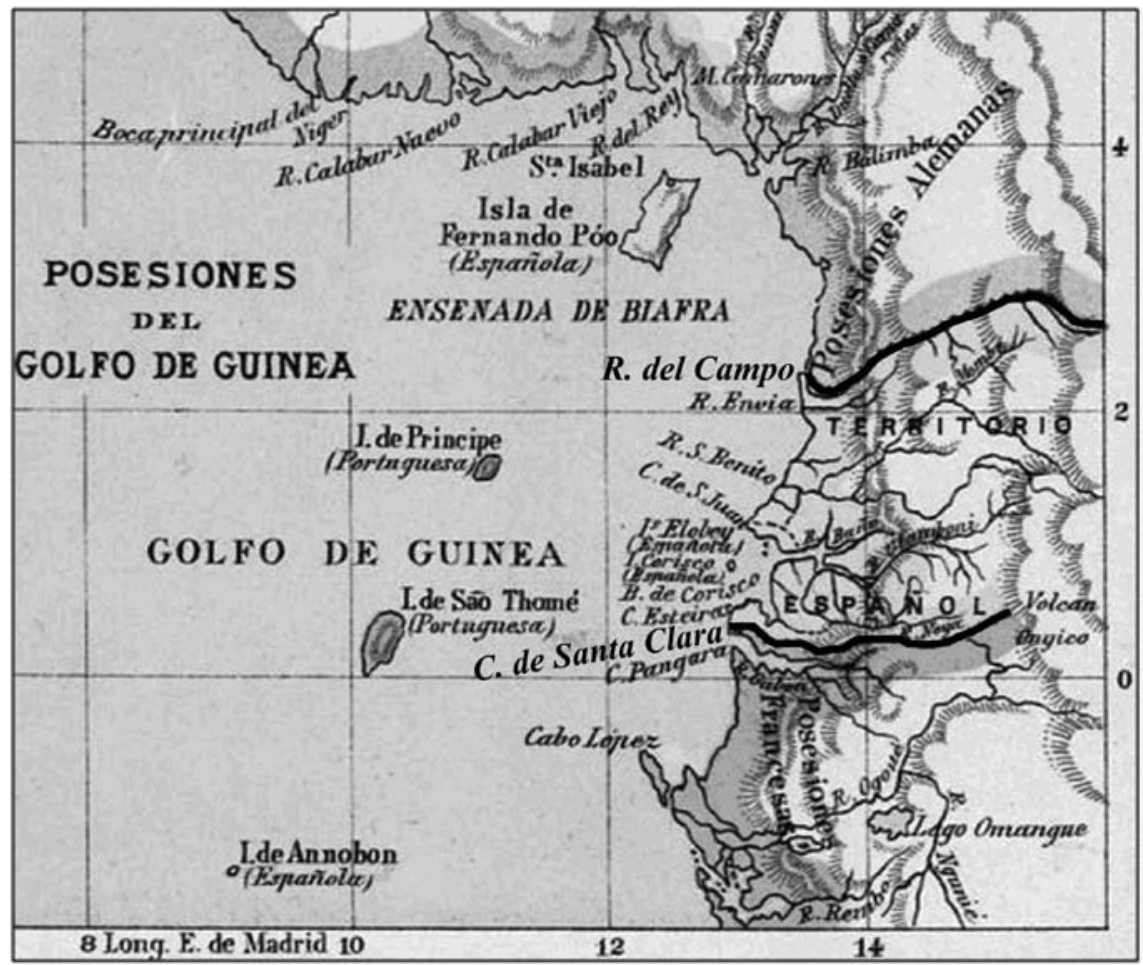

Mapa 1. Espacio costero comprendido entre el río Campo y el cabo Santa Clara, reivindicado por España en la región del Muni conforme a la propuesta realizada por el gobernador José de Barrasa. Fuente: Atlas Geográfico Universal (1898). Barcelona: Hermenegildo Miralles, p. 41 (adaptación). 
subgobernador de Elobey, Dionisio Shelly, por haber exigido el pago de una tasa a un buque francés que pretendía comerciar en el estuario del Muni, infringiendo, según él, el derecho reconocido de libre acceso al río; y la segunda para protestar por la presencia de banderas españolas en este mismo río.

Respecto al primer incidente, la respuesta de De Barrasa fue clara y tajante: nada podía objetar al respecto porque los derechos que debían pagarse en Elobey eran anteriores a la reunión del Congreso Internacional en París, pues figuraban en los presupuestos de 1885-1886 y empezaron a regir en 1 de julio de 1885, mucho antes de su llegada. En su opinión, la soberanía española sobre el Muni había quedado definitivamente confirmada cuando todas las naciones pidieron a España los derechos de libre acceso al río, un dato que demostraba el reconocimiento de su plena soberanía a nivel internacional, "pues sería ridículo pedir de nuestra Nación el libre acceso al Ródano o al Po» ${ }^{23}$.

En cuanto al segundo, bastaba recordar que, desde finales de junio, ningún buque español había entrado en el Muni, por lo que si allí aparecían banderas españolas enarboladas, debía atribuirse solo a las mayores simpatías por España que sus habitantes libremente expresaban. En su réplica, De Barrasa no se olvidó de recordar a su homólogo francés que consideraba, contrariamente al criterio del comandante del Basilic, quien pretendía que el río Benito era francés, "como territorio español desde la orilla izquierda del río Campo hasta y con la bahía de Corisco", con lo cual le daba a entender que, mientras los gobiernos supremos no alcanzaran un acuerdo que modificara este criterio, él no daría nunca su brazo a torcer ${ }^{24}$.

Esta diferencia de parecer dio pie a una situación mucho más delicada cuando el presidente de la República declaró por decreto que Punta Botica (Ouvinia, en la toponimia francesa), un saliente en el lado sur del río Muny a pocas millas de la desembocadura, pertenecía a Francia, razón por la que el comandante del aviso Laprade recibió instrucciones del comandante superior del Gabón (De Brazza) de arbolar en ella la bandera francesa, con lo cual obligaba a los naturales a retirar el pabellón español que allí ondeaba por su propia iniciativa, lo mismo que en otros puntos de los ríos Noya y Utamboni, tributarios de esta misma margen sur. La contundencia con la que

23. AGA. A-G. C 81/7071. Respuesta del gobernador De Barrasa a las dos comunicaciones del comisario superior francés. Río Muni, 6 de agosto de 1886.

24. AGA. A-G. C 81/7071. Respuesta a las dos comunicaciones del comisario superior de los establecimientos franceses en el golfo de Guinea. Elobey, 7 de julio de 1886. El borrador de este documento se conserva en el archivo familiar Guilloto-Barrasa de Cádiz (AFGB). Los borradores conservados en este archivo familiar han permitido al investigador gaditano Fernando Guilloto y González, casado con una nieta del gobernador, comentar algunas de las actuaciones de José de Barrasa en la defensa del Muni en su artículo «Un gaditano héroe del Muni» (Ateneo: Revista cultural del Ateneo de Cádiz, 7, 2007a, 144-148). Véase asimismo el perfil biográfico de José de Barrasa y Fernández de Castro trazado por este mismo autor en: Fernando Guilloto y González (2007b), José de Barrasa y Fernández de Castro: Marino y político gaditano (1847-1929), Cádiz, Fernando Guilloto y González. 
De Barrasa manifestó al comandante la imposibilidad de permitirlo, a menos que pasase por encima de las fuerzas a sus órdenes, hizo que éste desistiera, y propuso como solución amistosa «dejar que se colocasen banderas francesas al lado de las españolas para marcar su protesta» 25 .

Para zanjar el asunto, De Barrasa le hizo ver que la bandera «no significaba la materialidad de la lanilla, sino que cubría el territorio donde estaba arbolada, por lo que no podía consentir se pusiese ninguna otra en donde ella flotaba ${ }^{26}$. Al final, en vista de que los jefes de los poblados se mostraban reacios a aceptar la propuesta de ser súbditos franceses, incluso ofreciéndoles tentadores regalos, el comandante del Laprade manifestó al gobernador que podía regresar tranquilo a Fernando Poo, «en la seguridad de que no se tocaría ninguna bandera española».

Confiando en su palabra, De Barrasa decidió regresar sin pérdida de tiempo, entre otras razones, porque necesitaba reparar la maltrecha Ligera y recibir a la marinería de refuerzo que había llegado de la Península en un transporte alemán; no sin antes agradecer con diversos regalos y un significativo aumento de sueldo a los jefes la conducta que habían observado, en especial a Gandu, máxima autoridad de la zona. Asimismo, antes de partir, dio instrucciones al subgobernador de Elobey (José de Ibarra) para que tratase por todos los medios a su alcance de garantizar la libertad de comercio en el Muni y evitar que ningún buque de guerra de otro país se interpusiera en los asuntos del río ${ }^{27}$.

Al poco de haber llegado a Santa Isabel, De Barrasa supo que los franceses habían arbolado su bandera en Punta Botica, con lo cual faltaron a la palabra dada por el comandante del Laprade y sin que se diera oposición material por parte del subgobernador. Firme en lo que consideraba su deber, decidió regresar de inmediato al Muni, incluso sin esperar a que se realizase el cambio de férulas pendiente en la Ligera. Una vez in situ, al comprobar que ya no había ningún buque francés en el río, decidió dirigir una durísima carta de protesta a De Brazza, su homólogo francés en el Gabón, en la que no dudó en manifestarle que, si él hubiese estado presente, podía tener la certeza de que «hubiese sellado con sangre» los odiosos actos llevados a cabo contra el pabellón español.

A partir de este momento, el gobernador De Barrasa, siempre dispuesto a conjugar honor, firmeza y diplomacia en el cumplimiento de su deber, optó por dirigir sistemáticamente cartas de protesta a De Brazza cada vez que consideraba vulnerados los términos pactados en el statu quo, algo que sucedía muy a menudo, a fin de evitar que sentaran precedentes que pudieran hacerse valer en las negociaciones que se seguían en París. Sin embargo, sus quejas

25. AGA. A-G. C 81/7071. Informe reservado al ministro de Ultramar. A bordo de la goleta Ligera. Elobey, 7 de agosto de 1886.

26. AFGB. Informe sobre los hechos acaecidos con el aviso Laprade.

27. AGA. A-G. C 81/7071. Instrucciones del gobernador De Barrasa al subgobernador de Elobey. Elobey, 7 de agosto de 1886. 
durante los breves meses que estuvo como gobernador interino solo constituyeron un preludio de lo que serían sus actuaciones tres años más tarde, cuando fue nombrado gobernador titular de Fernando Poo.

\section{Las presiones francesas sobre Bata y río Benito}

El inicio de acciones de mayor fricción entre las autoridades coloniales españolas y francesas se dio a finales de 1889, cuando el gobierno gabonés creó en Bata - donde ya tenía desplegado un destacamento de doce hombres indígenas - una "oficina de correos» y declaró que, a partir del 1 de enero de 1890, exigiría una contribución a las factorías allí establecidas. Conforme al parte de campaña del comandante del Isabel II, en Bata, además del citado destacamento, existía una misión de la congregación del Saint-Esprit, compuesta por dos misioneros y tres factorías, dos alemanas y una inglesa, a las que solo se les permitía izar la bandera francesa ${ }^{28}$. Indeciso a causa de la ambigüedad de las disposiciones comunicadas desde Madrid, el gobernador saliente, Antonio Moreno de Guerra, pidió que quien fuera destinado a relevarle acudiera a Fernando Poo con «instrucciones claras» al respecto ${ }^{29}$. Nadie más idóneo para gestionar tan flagrante ruptura del statu quo que Don José de Barrasa, el primero en denunciar los tejemanejes del comisario De Brazza.

Estando De Barrasa ya de camino para tomar posesión de su nuevo cargo como máxima autoridad de la colonia, el gobernador provisional, José Gómez de Barreda, cursó un telegrama cifrado al ministro de Ultramar para poner en su conocimiento que los franceses acababan de establecer una fuerza militar en río Benito, la cual había exigido al vapor español Fernando Poo documentos de aduana y el cobro de derechos sanitarios, con grave infracción del statu quo ${ }^{30}$.

A la mańana siguiente de su llegada, De Barrasa, informado de la situación y fiel a su estilo, dirigió sin demora una carta de protesta al Comisario del Gabón y el Congo francés por las actuaciones del cañonero Basilic en río Benito, al tiempo que redactaba una comunicación para el comandante del Fernando Poo, en la que le daba instrucciones precisas sobre la conducta que debía observar frente a las ilícitas labores de policía que los franceses pretendían ejercer en el río, señalándole que ni les debía pagar absolutamente ninguna clase de gravámenes, ni tampoco permitir que examinaran ni visaran ninguna clase de documentación, dado que el río Benito pertenecía «de todo derecho» a España ${ }^{31}$.

28. AFGB. Extracto del parte de campaña que el comandante del Isabel II da, a vuelta del viaje que hizo a nuestras posesiones de África del 22 de febrero al 26 de marzo de 1890.

29. AGA. A-G. C 81/7059. Oficio del gobernador Antonio Moreno Guerra al ministro de Ultramar.

30. AGA. A-G. C 81/7065. Telegrama cifrado del gobernador interino al ministro de Ultramar. Fernando Poo, 29 de noviembre de 1890.

31. AGA. A-G. C 81/7065. Comunicación al comandante del vapor Fernando Poo. Santa Isabel, 23 de diciembre de 1890 . 
Conforme a los términos de la carta de protesta, el incidente lo había provocado un pasajero del vapor español cuando, al bajar a tierra, había regalado una bandera y una escopeta de caza a un jefe nativo, manifestándole que aquellos territorios estaban bajo la protección de España y no de Francia. Según De Barrasa, la conducta del viajero había sido una reacción individual de un civil al inadmisible proceder del comandante del Basilic, denunciado en su día por el gobernador interino José de Ibarra, por recorrer el río Benito «invitando a los Jefes de los pueblos a que entregasen los nombramientos y banderas que tenían de los agentes españoles, ofreciéndoles regalos y amenazándoles si no accedían». Resultaba, pues, inadmisible declarar infringido el statu quo haciendo responsable «a todo un buque de la conducta de un simple pasajero en tierra». En todo caso, las vulneraciones debían entenderse en sentido contrario, ya que la infracción de un civil no tenía paragón con los atropellos cometidos por un oficial de la Armada en el ejercicio de sus funciones.

A pesar de hallarse ahora frente a rupturas del statu quo mucho más graves que las vividas en su mandato anterior, De Barrasa introduce una novedad significativa en las misivas que dirige a su homólogo francés: en ningún lugar lo amenaza con usar la fuerza para responder a los agravios ni en sellar con sangre las afrentas, sino que se limita a hacer constar por escrito su protesta con mayor o menor dureza. Debe protestar y protesta a De Brazza por su «incalificable tentativa de cerrar al "Fernando Poo" el río Benito»; por sus continuos ataques a la libertad comercial al dictar «reglas para el servicio sanitario e inspección de la documentación de los buques e imposición a éstos de derechos»; por negar el derecho de los naturales a arbolar el pabellón español; por pretender ser una vulneración del statu quo el hecho de que el subgobernador de Elobey viaje con frecuencia a bordo del Fernando Poo, etc. ${ }^{32}$. Lo hace con firmeza, pero sin recurrir a la intimidación, y da cuenta detallada de todo ello a los ministros de Estado y Ultramar ${ }^{33}$.

No cabe duda de que entre las instrucciones «claras» que desde Madrid se dieron a De Barrasa en su segundo nombramiento como gobernador de las posesiones españolas del golfo de Guinea estaba la de respetar escrupulosamente los términos del statu quo, a fin de evitar cualquier incidente violento que pudiera dañar una solución diplomática del diferendo.

\section{La instrumentalización de las misiones religiosas en el despliegue francés}

A pesar de haber empezado a mover sus fichas en río Benito y Bata, el flanco por donde el comisario De Brazza pensaba poner realmente en jaque a las

32. AGA. A-G. C 81/7065. Comunicación de protesta al comisario general del Gabón y del Congo francés por las actuaciones del cañonero Basilic en Río Benito. Santa Isabel, 23 de diciembre de 1890 .

33. AGA. A-G. C 81/7065. Comunicación al ministro de Ultramar sobre las actuaciones de Mr. Brazza. Santa Isabel, 28 de diciembre de 1890. Un borrador del mismo documento puede encontrarse en el AFGB. 
pretensiones territoriales españolas era río Muni, por lo que el paso siguiente fue negar la soberanía de España sobre Elobey, un espacio en el que, según De Barrasa, el Gobierno de Fernando Poo tenía establecida su autoridad «muchísimos años antes del statu quo» ${ }^{34}$. Atónito por este nuevo dislate de su «turbulento» opositor, confiesa al ministro de Estado que «mientras Mr. Brazza esté al frente del Gaboon no tendremos un momento de tranquilidad» ${ }^{35}$.

El asalto francés al Muni tomó cuerpo a principios de 1891 con la fundación de una misión espiritana en Punta Kogo, situada en el lado norte del estuario, en la desembocadura misma del río Congüe, con la excusa de que las misiones religiosas no podían ser consideradas como «oficiales» y de que aquellos territorios nunca habían sido desmembrados por la Santa Sede de la Prefectura Apostólica del Gabón.

Según De Barrasa, los misioneros allí establecidos con grave violación del statu quo no solo perseguían fines espirituales, sino que también se dedicaban a decir a los jefes «que todo aquello era de Francia y no debían poner ninguna bandera que no fuera la francesa». Así, en su carta de protesta, al comprobar la desfachatez con que De Brazza añade la cruz a la espada en sus propósitos anexionistas, advierte que si «S.S. no considera las Misiones como oficiales cuando autoriza su establecimiento, quedamos nosotros también en libertad de establecerlas, lo que hasta ahora no se había hecho por nuestro escrupulosísimo respeto al statu quo» ${ }^{36}$. Para más rémora, el 6 de febrero fue desgarrada la bandera española que había en Kogo por trabajadores de la misión y existía la certeza que, desde esta nueva sede apostólica, se daban a los naturales «verdaderos fusiles de pistón». Además, el capitán del buque de guerra Saphir había amenazado «a un Jefe indígena de quemar el pueblo si no arriaba la bandera española» ${ }^{37}$.

Cuando trasladó estos nuevos quebrantamientos del statu quo al ministro de Ultramar, De Barrasa le hizo ver como el despliegue de misiones espiritanas demostraba el propósito constante de Francia de aumentar su influencia en la región a costa de España, algo que merecía ser respondido de la misma manera fundando enseguida dos misiones españolas en los dos puntos más en litigio: río Muni y río Benito. Para ello, le solicitó autorización telegráfica y crédito suficiente, convencido de que las nuevas fundaciones no iban a ocasionar ningún conflicto diplomático, porque los primeros en romper el statu quo habían sido los franceses. Creía, además, que no sería necesario ampliar el presupuesto ni tampoco el número de misioneros existente, ya que sería posible trasladar a los misioneros de Cabo San Juan a las nuevas sedes, una

34. AGA. A-G. C 81/7065. Respuesta a las quejas del comisario general francés por sus continuas infracciones del statu quo. Santa Isabel de Fernando Poo, 31 de enero de 1891.

35. AGA. A-G. C 81/7065. Trasladando al ministro de Estado las pretensiones francesas sobre Elobey. Santa Isabel de Fernando Poo, 31 de enero de 1891.

36. AGA. A-G. C 81/7067. Protestando contra el establecimiento de misiones francesas en Punta Kogo. Gobierno General de Fernando Poo, 12 de marzo de 1891.

37. AGA. A-G. C 81/7067. Protestando por haber sido desgarrada la bandera española en el pueblo de Kogo. Gobierno General de Fernando Poo, 20 de marzo de 1891. 
misión que podría cerrarse temporalmente por estar en un punto de indiscutible pertenencia a España ${ }^{38}$. En Ultramar, sin embargo, no se juzgó útil precipitarse con autorizaciones telegráficas, porque antes debía ser consultado el Ministerio de Estado y tener la certeza de que aquellas acciones no provocarían malestar en París.

\section{La voluntad francesa de arrinconar a España}

A finales de marzo, el subgobernador de Elobey puso al corriente a De Barrasa de tres nuevas quiebras flagrantes del statu quo. La primera en Punta Elobey, donde un destacamento de negros armados había arrebatado por la fuerza la bandera española al práctico de la lancha Trinidad, «diciéndole que por allí no podía pasar ningún bote con bandera española». La segunda en la isla de Corisco, donde no se permitía a los naturales «pescar en el sur de la bahía, entre el cabo Esteiras y el Mundah", como tampoco traficar con el pueblo de Moka. Y la tercera en las factorías extranjeras instaladas en el Muni, a las que se cobraba un pequeño impuesto, que precisamente por su pequeñez no perseguía otro objetivo que marcar un reconocimiento de autoridad ${ }^{39}$.

La vaguedad de las indicaciones que recibía desde Madrid cuando informaba de los quebrantamientos del statu quo provocaban en De Barrasa un sentimiento de cansancio y frustración, cada vez más acusado a medida que comprobaba cómo los franceses seguían avanzando en sus objetivos mientras que a él solo se le instigaba a ser escrupuloso y prudente en el cumplimiento del statu quo. Consciente de cómo Brazza sabía aprovechar la pasividad del Gobierno español para progresar desde todos los frentes, comenzó a insistir a los ministros de Estado y Ultramar de su «completa convicción de la necesidad de terminar el litigio» ${ }^{40}$.

La voluntad francesa de arrinconar a España en su reducto de Cabo San Juan obrando, según De Barrasa, "como si este pacto internacional no existiese», o cuando sí lo reconocían, pretendiendo aplicarlo "par mesure gracieuse» ${ }^{41}$, se hizo del todo evidente en el verano de 1891 , cuando sus acciones se multiplicaron en todas partes: en el río Mundah despojaron a los tripulantes de un bote de Corisco de la caña que llevaban para traficar, con el argumento de que «allí no comerciaba nadie sin una orden de las autoridades del Gabón». En río Benito y Bata pretendieron exigir derechos a la casa ingle-

38. AGA. A-G. C 81/6947. E 10. Misiones: establecimiento de una en el río Muni y de otra en el Benito. Oficio del gobernador José de Barrasa al ministro de Ultramar. Santa Isabel, 20 de enero de 1891.

39. AGA. A-G. C 81/7065. Comunicación de protesta por el incidente promovido en Punta Elobey. Santa Isabel de Fernando Poo, 5 de mayo de 1891. El borrador de este documento se encuentra en el AFGB.

40. AGA. A-G. C 81/7073. Informando al ministro de Estado sobre una expedición por el interior del río Benito. Santa Isabel de Fernando Poo, 6 de mayo de 1891.

41. AGA. A-G. C 81/7065. Reclamación dirigida al teniente gobernador del Congo francés. Santa Isabel de Fernando Poo, 27 de octubre de 1891. 


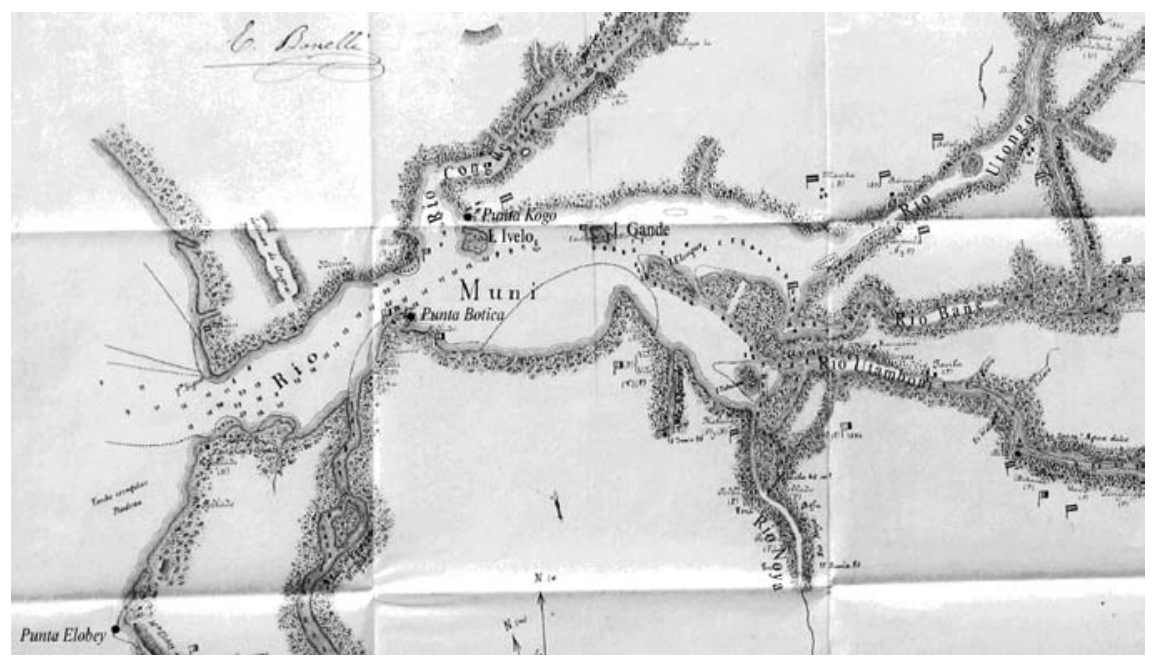

Mapa 2. Principales espacios en el estuario del río Muni impugnados por De Barrasa frente a las pretensiones de ocupación del comisario De Brazza.

Fuente: plano de Río Muni de Emilio Bonelli (1890). Archivo General Militar de Segovia (adaptación).

sa Hatton Cookson, cuando "desde el momento que se estableció el statu quo, quedaban obligadas las dos Naciones a no establecer absolutamente ninguna clase de impuestos donde antes no se cobrasen, y a no aumentar los antiguos» ${ }^{42}$. En la misma Bata, el jefe de puesto francés manifestó que tenía orden de visitar a los comandantes de los buques de guerra de todas las naciones, lo cual constituía "un acto de jurisdicción contrario al statu quo» ${ }^{43}$; y en el sur del río Campo, el capitán del Fernando Poo no pudo embarcar a veinte hombres que tenía contratados porque «se le exigió el cumplimiento de ciertas formalidades por un agente francés», trámites que no quiso cumplimentar, siguiendo las instrucciones recibidas del gobernador, "porque constituían una infracción del statu quo" ${ }^{44}$. A sus ojos, los perjuicios que estaba causando la vigencia del statu quo resultaban «incalculables», porque cuando se pactó se cometieron tres errores: el primero porque no se estipuló el derecho de España a ejercer la policía en el río Muni y costa norte; el segundo porque su misma vaguedad permitía que los franceses pudieran interpretarlo conforme

42. AGA. A-G. C 81/7065. Protesta dirigida al comisario general del Congo francés por haber exigido derechos a la casa Hatton Cookson. Santa Isabel de Fernando Poo, 7 de noviembre de 1891.

43. AGA. A-G. C 81/7073. Comunicación de protesta por los hechos acecidos en el río Mundah. Santa Isabel, 30 de julio de 1891.

44. AGA. A-G. C 81/7065. Protesta al comisario general del Congo francés por las exigencias del comandante del Basilic al capitán del Fernando Poo. Santa Isabel de Fernando Poo, 25 de septiembre de 1891. 
a sus intereses, y el tercero porque, conociéndose los términos de este pacto, se había mantenido la colonia en absoluto abandono de fuerzas navales, precisamente cuando eran más necesarias ${ }^{45}$.

Por eso, para todas y cada una de estas infracciones, el gobernador José de Barrasa y Fernández de Castro tramitó cartas de protesta al comisario general del Gabón y a los comandantes de los buques de guerra franceses a su servicio, a la vez que daba de ellas detallada cuenta a los ministros de Estado y Ultramar, consciente de que no debía consentir que ninguna pudiera pasar desapercibida y sentar precedente. Sin duda, unos principios y un proceder que heredaron los gobernadores que le sucedieron en el cargo y que permitieron preservar para España, a pesar de la dejadez de su clase política, por lo menos una mínima parte de aquellos territorios a los que la Sociedad Española de Africanistas y Colonistas aspiraba en suelo africano.

\section{Referencias bibliográficas}

Carrasco González, Antonio M. (2007). Derecho colonial en África y su aplicación al origen del ordenamiento español en Guinea (1777-1858). Madrid: Servicio de publicaciones de la Facultad de Derecho de la Universidad Complutense.

Castro Antolín, Mariano L. de y Calle Muñoz, Ma Luisa de la (1992). Origen de la colonización española en Guinea Ecuatorial (1777-1860). Valladolid: Universidad de Valladolid.

Cerarols Ramírez, Rosa (2008). L’imaginari colonial espanyol del Marroc: Geografia, gènere i literatura de viatges (1859-1936). Universidad Autónoma de Barcelona. Facultad de Filosofía y Letras. Tesis doctoral dirigida por la Dra. Ma Dolors Garcia Ramon.

Creus i Boixaderas, Jacint (1998). Action missionaire en Guinée Équatoriale, 18581910: Perplexités et naïvités à l'aube de la colonization. Universidad de París VII. Tesis doctoral inédita.

Díaz Matarranz, Juan José (2005). De la trata de negros al cultivo del cacao: Evolución del modelo colonial español en Guinea Ecuatorial de 1778 a 1914. Vic: CEIBA.

García Cantús, María Dolores (2006). Fernando Poo: Una aventura colonial española. I: Las islas en litigio: entre la esclavitud y el abolicionismo, 1777-1846. Vic: CEIBA.

Garcia Ramon, Maria Dolors; Nogué, Joan y Zusman, Perla (2008) (eds.). Una mirada catalana a l'Àfrica: Viatgers i viatgeres dels segles XIX $i$ XX (1859-1936). Lleida: Pagès Editors.

González Bueno, Antonio; Gomis Blanco, Alberto (2007). Los territorios olvidados: Naturalistas españoles en el África hispana (1860-1936). Madrid: Ediciones Doce Calles.

Guilloto y González, Fernando (2007a). «Un gaditano héroe del Muni». Ateneo: Revista cultural del Ateneo de Cádiz, 7, 144-148.

45. AGA. A-G. C 81/7065. Trasladando al ministro de Ultramar algunas consideraciones sobre la falta absoluta de respeto del statu quo por parte francesa. Santa Isabel, 30 de junio de 1891. 
- (2007b). José de Barrasa y Fernández de Castro: Marino y político gaditano (18471929). Cádiz: Fernando Guilloto y González.

Iradier Bulfy, M. (1885). «Segundo viaje». En: Jiménez Fraile, Ramón (ed.). África: Un español en el golfo de Guinea. Madrid, p. 163-189: Mandadori.

Nerín Abad, Gustau (1997). Guinea Ecuatorial: Historia en Blanco y Negro. Barcelona: Península.

Pedraz Marcos, Azucena (2000). Quimeras de África: La Sociedad Española de Africanistas y Colonistas. El colonialismo español de finales del s. XIX. Madrid: Polifemo.

Rodríguez Esteban, José Antonio (1996). Geografía y colonialismo: La Sociedad Geográfica de Madrid (1876-1936). Cotoblanco: Ediciones de la Universidad Autónoma de Madrid.

Sanz Casas, Gonçal (1983). Política colonial y organización del trabajo en la isla de Fernando Poo (1880-1930). Universidad de Barcelona. Facultad de Geografía e Historia. Tesis doctoral.

Vilaró i GüEll, Miquel (2011). La colonización de la cruz en la Guinea española. Vic: CEIBA.

Villanova Valero, José Luis (2004). El Protectorado de España en Marruecos: Organización política y territorial. Barcelona: Bellaterra. 